\title{
Examining the effect of in vitro toothbrushing and the effect of different whitening toothpaste usages on the color change of a nanofilled composite
}

\author{
(1) Funda Demir, (1) Elif Aybala Oktay, (1) Serpil Karaoğlanoğlu, (1) Fulya Toksoy Topçu, (1) Ertürk Bilgeç, \\ (1) Numan Aydın
}

University of Health Sciences Turkey, Gülhane Faculty of Dentistry, Department of Restorative Dental Treatment, Ankara, Turkey

\section{Date submitted:}

10.01.2020

Date accepted:

20.08.2020

Online publication date:

15.03.2021

\section{Corresponding Author:}

Funda Demir MD PhD, University of Health Sciences Turkey, Gülhane Faculty of Dentistry, Department of Restorative Dental Treatment, Ankara, Turkey

fundademir2004@yahoo.com

ORCID:

orcid.org/0000-0002-2260-1638

Keywords: Composites, discoloration, whitening, toothpaste

\begin{abstract}
Aims: Whitening has recently been one of the most demanded treatments in modern dentistry practice. The authors tested three hypotheses related to color changes on universal nanofilled composite resin samples promoted by in vitro tooth brushing with the usage of different whitening toothpastes.

Methods: For this in vitro study, a total of 8 different whitening toothpaste test groups and a control group, where each test group included 10 randomly selected composite resin samples, were formed. After all composite samples were light cured and polished, they were stored in distilled water, kept immersed in red wine and subjected to brushing, consecutively. Colors of the composite samples were measured by using a colorimeter device after each process.

Results: For all test groups, we observed that the discolorations on the samples due to immersion in red wine were reduced significantly after brushing with or without a toothpaste. Color improvement promoted by one whitening toothpaste brand containing hydrogen peroxide as bleaching agent was significantly higher than in the control group. Statistically similar color improvement values were observed among whitening toothpaste test groups, when compared to each other.

Conclusions: From the results of our study, it can be concluded that: Firstly, only one of the whitening toothpastes showed statistically significant color improvement over the control group; secondly, the color improvements promoted by whitening toothpastes, used in this study, were statistically similar.
\end{abstract}

\section{Introduction}

Dental whitening has recently been one of the most demanded treatments in modern dentistry practice. Individuals desire a whiter tooth color to have an attractive smile (1). The most important disadvantage of composite resins, commonly used in the teeth restorations due to increasing interest in dental aesthetics, is the colorations caused by internal and external factors $(2,3)$. The internal factors that cause coloration are chemical dissolution of the resin matrix, the structure of the composite resins (4) and the fillers due to incomplete polymerization (5). Extrinsic factors, on the other hand, create color change on the outer surface (6). In the literature, it has been shown that chromogenic beverages such as red wine and coffee can lead to surface colorations on composite restorations (4,7-9).

These surface colorations in composite restorations can be partially or completely eliminated by brushing with toothpaste (10). Among the methods that people use to have better aesthetic appearances, using whitening toothpastes is very common.

In order to provide the teeth to be perceived whiter, optical agents such as blue pigment (blue covarine) are added into the ingredients of some toothpastes. This type of toothpastes allows the teeth to appear whiter right after brushing, by enabling the optical agents, which create a yellow-to-blue color change in the teeth, to be stored on the tooth surface. This has been proven in many clinical and in vitro studies $(11,12)$. 
The bleaching process takes place mainly by the conversion of peroxides into free radicals. During the bleaching process, long-chained organic molecules that cause coloration are oxidized by peroxide agents with free oxygen and separated into smaller molecules with lighter colors. These compounds are rendered colorless by cleavage of double bonds in the chain, separation of compounds, or oxidation of other chemical structures (13). Hydrogen peroxide is added to some whitening toothpaste ingredients in low concentrations to benefit from this feature of peroxides.

The charcoal, the first use of which for oral hygiene dates back to Hippocrates of Ancient Greek (14), is included in the formulas of some whitening toothpastes to improve bleaching efficiency. However, in the literature, it is stated that there is not sufficient scientific evidence for the cosmetic and health benefits of commercially available charcoal-based toothpastes (15).

The enzyme, included in whitening toothpastes, provides a whitening effect as a result of removing the stained biological film layer by breaking down the organic molecules of the pellicle (16).

\section{Hypotheses Tested}

In this in vitro study, we tested three hypotheses: First, stating that the color improvement promoted by brushing (with or without toothpaste) would be statistically significant; second, stating that the color improvement promoted by whitening toothpaste would be significantly higher than the one without toothpaste (control group); last, stating that the color change promoted by different whitening toothpaste brands would not be significant when compared to each other.

\section{Methods}

In this in vitro study, we used a light-curing universal nanofilled composite resin (Filtek Ultimate Universal Restorative A1 Enamel - 3M ESPE, St. Paul, USA) as aesthetic dental restorative material.
We used the following whitening toothpastes; R.O.C.S. Sensation Whitening (EuroCosMed, Russia), Splat Blackwood (Splat-Cosmetica, Moscow, Russia), Curaprox Black is White (Curaden Pharma GmbH, Switzerland), Colgate Optic White (Colgate, New York, USA), Signal White Now CC (Unilever, France), Parodondax Whitening (GlaxoSmithKline, Middlesex, UK), Sensodyne True White (GlaxoSmithKline, EU) and Beverly Hills Formula Perfect White Black (Purity Laboratories, Ireland). The bleaching ingredients contained in whitening toothpastes used in our study are shown in Table 1.

\section{Preparation of Samples and Test Groups}

90 disc-shaped composite samples $(n=90)$ were prepared in the metal mold with a diameter of $6 \mathrm{~mm}$ and a thickness of 2 $\mathrm{mm}$ (17). After covering transparent mylar strip on samples, they were light cured under a $1 \mathrm{~mm}$ glass lamina for 20 seconds by using the Woodpecker LED-B light device (Guilin Woodpecker, Guangxi, China). Then, for the finishing and polishing of each composite sample; dry, medium, fine and superfine OptiDisk (Part No. 4200, Kerr, Switzerland) polishing discs were used for 10 seconds each, consecutively. We polished the same side of the samples and put a mark on the non-polished sides for standardization. All samples were stored in distilled water for 4 weeks at room temperature (18). A total of 9 test groups, each including 10 randomly selected $(n=10)$ composite samples, were formed to test 8 different whitening toothpastes and one control group (artificial saliva). All samples were kept in closed containers at room temperature during every step of the study.

\section{Measuring the Color Change}

Surface color was measured three times on the center of the polished side of each sample by using a colorimeter device (Minolta CR-321, Osaka, Japan) and the mean values were recorded in every step of the study. Before each measurement cycle, the colorimeter device was calibrated for $L, a, b$ values ( $L=93.05, a=-4.84, b=6.95)$. Calibrations were performed in the same medium using the white calibration plate. The standard

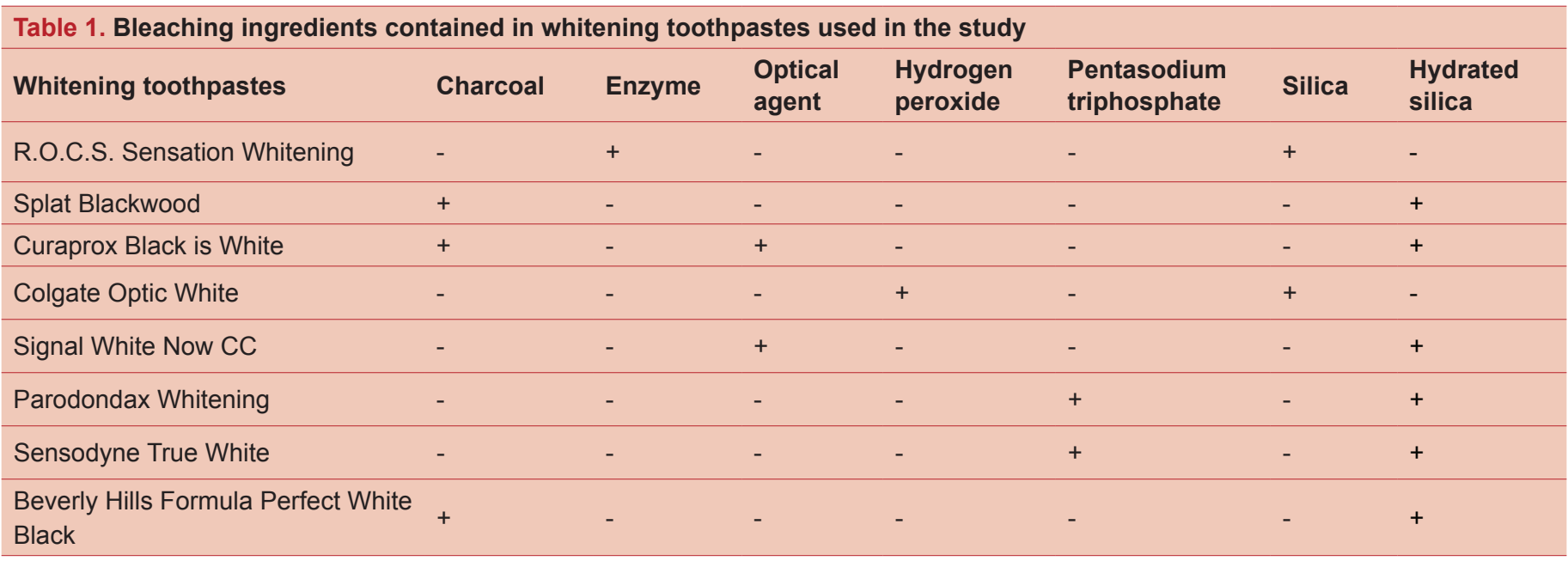


white background was used during the measurements of the composite samples and the calibration of the instrument was checked before each measurement.

After all samples in all test groups had been kept immersed in artificial saliva for 24 hours at room temperature to help the formation of a pellicle, initial color values of the samples were measured.

Following to this process, the samples were kept immersed in red wine (Kalecik Karası 2014, contains 12\% alcohol) for 24 hours; washed with tap water for 10 seconds; and dried with paper, and the color measurements mentioned above were done for the second time.

At the last step, composite samples belonging to different test groups were brushed with different whitening toothpastes dedicated to that group. On the other hand, the samples in the control group were brushed only with artificial saliva. Toothpastes were mixed with artificial saliva at a rate of $1 / 2$ (by weight) before brushing. We used Oral-B Genius 8000 (Braun, Germany) electric toothbrush with Oral-B CrossAction (Braun, Germany) brush head. Composite resins were subjected to brushing manually for $1 \mathrm{~min}$ with a standardized pressure (pressure sensor gives a visual notification through the LED SmartRing, which illuminates red when too much pressure is applied) and 10,500 oscillations/rotations per minute. The samples were washed with tap water for 10 seconds and dried with paper, and then, the final color measurements were done.

\section{Statistical Analysis}

Statistical analyses were performed with SPSS 22.0 (Statistical Package for Social Sciences, IBM Inc., USA) software. To evaluate the color change in test groups after each process (immersed in red wine, brushing), dependent samples t-test (paired-t) was employed. The differences between test groups were analyzed by using ANOVA and Tukey post-hoc tests. The results were evaluated at $(p<0.05)$ significance level.

\section{Results}

It was observed that the two consecutive processes, immersion in red wine for 24 hours and brushing with whitening toothpaste, affected the color of all samples, where $\Delta \mathrm{E} 1$ shows the color change after immersion in red wine and $\Delta \mathrm{E} 2$ shows the color change after brushing, both measured against the initial color of the samples. For all test groups, we observed that the discolorations on the samples which occurred after immersion in red wine were significantly reduced after brushing (with or without toothpaste), but not to the clinically acceptable level ( $\Delta \mathrm{E} 2 \geq 3.3$ for all test groups) (Table 2 ).

Regarding the effects of different whitening toothpaste brands on color change, it was observed that only the color improvement promoted by Colgate Optic White group was significantly higher than in the control group. Color improvement promoted by other whitening test groups was nonsignificant when compared to the control group (Table 3).

It was observed that the color improvement promoted by different whitening toothpaste brands was statistically similar, when compared to each other (Table 3).

Among the whitening toothpastes, the one containing hydrogen peroxide (Colgate Optic White) provided the best color improvement, whereas the one containing pentasodium triphosphate (Parodondax Whitening) provided the poorest color improvement (Table 1, 3).

\section{Discussion}

Whitening toothpastes have taken place among the dental whitening products that individuals can easily reach and apply as a result of their increased aesthetic expectations (19). However, the physical and chemical effects of whitening toothpastes, containing different active ingredients, on the composites commonly used in the restoration of teeth are not well known.

In this study, we investigated the change in color of the samples of universal nanofilled composite resin material, which were immersed in red wine, after being brushed with eight different brands of whitening toothpastes.

\begin{tabular}{|lll|}
\hline Table 2. $\Delta \mathrm{E} 1$ and $\Delta \mathrm{E} 2$ average and standard deviation & $\begin{array}{l}\Delta \mathrm{E} \text { (color change after } \\
\text { immersion in red wine, compared } \\
\text { to initial color) }\end{array}$ & $\begin{array}{l}\Delta E 2 \text { (color change after } \\
\text { brushing, compared to initial } \\
\text { color) }\end{array}$ \\
\hline Test groups & $9.65 \pm 1.604$ & $5.86 \pm 1.55$ \\
\hline R.O.C.S. Sensation Whitening & $9.61 \pm 2.257$ & $5.78 \pm 1.367$ \\
\hline Splat Blackwood & $10.27 \pm 2.325$ & $6.55 \pm 2.193$ \\
\hline Curaprox Black is White & $11.33 \pm 1.967$ & $6.87 \pm 1.923$ \\
\hline Colgate Optic White & $9.35 \pm 0.884$ & $6.02 \pm 1.961$ \\
\hline Signal White Now CC & $9.59 \pm 3.293$ & $5.78 \pm 1.062$ \\
\hline Parodondax Whitening & $11.10 \pm 1.444$ & $7.71 \pm 2.509$ \\
\hline Sensodyne True White & $9.76 \pm 1.085$ & $6.90 \pm 1.702$ \\
\hline Beverly Hills Formula Perfect White Black & $9.87 \pm 3.141$ & $7.75 \pm 3.586$ \\
\hline Control Group (artificial saliva) & & $0.004^{*}$ \\
\hline${ }^{*}$ There is statistically significant difference $(p<0.05)$ & & $0.000^{*}$ \\
\hline
\end{tabular}




\begin{tabular}{|l|l|}
\hline Table 3. $\Delta \mathrm{E} 3$ average and standard deviation \\
\hline Test groups & $\begin{array}{l}\Delta \mathrm{E} 3 \text { (color change } \\
\text { after brushing, } \\
\text { compared to } \\
\text { immersion in red } \\
\text { wine) }\end{array}$ \\
\hline R.O.C.S. Sensation Whitening & $4.63 \pm 1.218 \mathrm{a}$ \\
\hline Splat Blackwood & $5.64 \pm 1.973 \mathrm{a}$ \\
\hline Curaprox Black is White & $6.32 \pm 2.395 \mathrm{a}$ \\
\hline Colgate Optic White & $7.10 \pm 2.855 \mathrm{ab}$ \\
\hline Signal White Now CC & $5.49 \pm 1.169 \mathrm{a}$ \\
\hline Parodondax Whitening & $4.47 \pm 2.329 \mathrm{a}$ \\
\hline Sensodyne True White & $4.49 \pm 1.188 \mathrm{a}$ \\
\hline $\begin{array}{l}\text { Beverly Hills Formula Perfect } \\
\text { White Black }\end{array}$ & $5.13 \pm 1.421 \mathrm{a}$ \\
\hline Control Group (artificial saliva) & $4.00 \pm 1.341 \mathrm{ac}$ \\
\hline *The same letter represents statistical similarity. Different letters indicate \\
statistically significant difference $(\mathrm{p}<0.05)$
\end{tabular}

The changes in the color of composite resins used in restorations, particularly in the anterior region, due to internal and external factors cause patient dissatisfaction and this is considered to be the aesthetic deficiency of materials $(20,21)$.

External factors causing the coloration on resin materials are various colored solutions such as red wine, coffee, cola and tea (5). In some studies, it has been stated that tea and coffee are major causes of coloration, while some other studies have reported that red wine increases coloration the most $(5,6,8)$. In our study, red wine was used for coloring the composite samples.

In our study, although two toothpastes (Curaprox Black is White and Signal White Now) containing optical agent as a bleaching agent partially removed the wine stains on the samples, the color improvement they provided was not at clinically acceptable level $(\Delta \mathrm{E} \geq 3.3)$.

In a study held by Philpotts et al. (18) (2017), investigating the effect of silica-based whitening toothpaste, containing blue covariant, on the color of the aesthetic restorations on extracted human teeth, the red wine stains on the samples were partially removed by a silica-based toothpaste; however, complete removal of the stains could not be achieved. In our study, two silica-based toothpastes (R.O.C.S. Sensation Whitening $\Delta \mathrm{E} 2=5.86 \pm 1.55$; Colgate Optic White $-\Delta \mathrm{E} 2=6.87 \pm 1.92)$ partially removed the red wine stains on the samples, but the color improvement they promoted was not at clinically acceptable level ( $\Delta E \geq 3.3$ ), similar to those observed by Philpotts et al. (18) (2017).

In the literature, it is stated that there is not sufficient scientific evidence for the cosmetic and health benefits of commercially available charcoal-based toothpastes (15). In our study, the charcoal-based toothpastes that we investigated showed statistically nonsignificant color improvement compared to other whitening toothpastes.
Although it is stated in the literature (22) that the enzymecontaining toothpastes significantly reduce external staining compared to others, the enzyme-containing toothpaste used in our study (R.O.C.S. Sensation Whitening) did not show a significant superiority in terms of the removal of the stains compared to those without enzymes.

Atalayın et al. (23) (2018) applied a one-year brushing simulation with three different whitening toothpastes (Pro-Expert Strong Teeth-Ijpana, 3D White Luxe Perfection-Ipana containing hydrated silica as abrasive ingredient; White Ruscello-GC containing calcium carbonate as abrasive ingredient) in their in vitro study, examining the after-brushing color changes of the four different composite resin samples (Componeer-Coltene, Brillant Ever Glow-Coltene, Essensia-GC, Harmonize-Kerr) stained with coffee. They observed that stains in all groups were removed at the clinically acceptable level $(\Delta \mathrm{E} \leq 2)$. In our study, however, the stains on the samples could not be eliminated at the clinically acceptable level after brushing with the toothpastes. This is considered to be due to the fact that the brushing simulation time (which is 15 days) applied in our study was much shorter.

Omata et al. (6) (2006), in their study on the coloration of microhybrid resin composite (Clearfil AP-X) samples, observed that the red wine stains were reduced when the stained composite samples were brushed for 10 seconds, with an electric toothbrush soaked in water without any toothpaste. Similarly, in our study, when the composite samples in the control group were brushed for 1 minute, with electric toothbrush soaked in artificial saliva, the red wine stains decreased.

In our study, it was observed that Colgate Optic White toothpaste, which contains hydrogen peroxide as bleaching agent, provided the best color improvement ( $\Delta \mathrm{E} 3=7.10 \pm 2.85$ ), which was significantly higher than in the control group (artificial saliva).

The current study had some limitations. We should consider that in vitro studies are difficult to fully reflect the oral environment. This situation may be related to the accuracy of the results about color changes on universal nanofilled composite resin samples, promoted by whitening toothpastes.

\section{Conclusion}

According to the results obtained in the present study, considering the in vitro study restrictions and regarding the hypotheses tested respectively, it can be concluded that:

- For all test groups, the discoloration on the samples that occurred due to immersion into red wine were reduced significantly after brushing (with or without toothpaste), but not to the clinically acceptable level $(\Delta \mathrm{E} \geq 3.3)$.

- Colgate Optic White toothpaste, containing hydrogen peroxide as bleaching agent, promoted the maximum color 
improvement on the samples, which was significantly higher than in the control group (artificial saliva).

- The color improvements promoted by whitening toothpaste brands, used in this study, were statistically similar, when compared to each other.

The results of this study showed that first and third hypotheses tested were true while the second one was partially true.

\section{Ethics}

Ethics Committee Approval: Our study was prepared in 2019, therefore, it was not presented to any ethics committee.

Informed Consent: It is not required for our study.

Peer-review: Externally peer-reviewed.

\section{Authorship Contributions}

Concept: F.D., E.A.O., Design: F.D., E.A.O., S.K., F.T.T., Data Collection or Processing: E.B., N.A., F.D., Analysis or Interpretation: F.D., E.A.O., S.K., Literature Search: F.D., E.B., N.A., Writing: F.D., E.A.O.

Conflict of Interest: No conflict of interest was declared by the authors.

Financial Disclosure: The authors declared that this study received no financial support.

\section{References}

1. Joiner A, Luo W. Tooth colour and whiteness: A review. Journal of Dentistry. 2017;67:3-10.

2. Asmussen E, Hansen EK. Surface discoloration of restorative resins in relation to surface softening and oral hygiene. Scand J Dent Res. 1986;94:174-177.

3. Bagheri R, Burrow MF, Tyas M. Influence of food-simulating solutions and surface finish on susceptibility to staining of aesthetic restorative materials. J Dent. 2005;33:389-398.

4. Shiozawa M, Takahashi H, Asakawa Y, Iwasaki N. Color stability of adhesive resin cements after immersion in coffee. Clin Oral Investig. 2015;19:309-317.

5. Ertaş E, Güler AU, Yücel AC, Köprülü H, Güler E. Color stability of resin composites after immersion in different drinks. Dent Mater J. 2006;25:371-376.

6. Omata Y, Uno S, Nakaoki Y, et al. Staining of hybrid composites with coffee, oolong tea, or red wine. Dent Mater J. 2006;25:125-131.

7. Bezgin T, Özer L, Tulga Öz F, Özkan P. Effect of toothbrushing on color changes of esthetic restorative materials. J Esthet Restor Dent. 2015;27(Suppl 1):65-73.

8. Catelan A, Briso AL, Sundfeld RH, Goiato MC, dos Santos $\mathrm{PH}$. Color stability of sealed composite resin restorative materials after ultraviolet artificial aging and immersion in staining solutions. J Prosthet Dent. 2011;105:236-241.

9. Genç G, Toz T. Rezin kompozitlerin renk stabilitesi ile ilgili bir derleme: Kompozit renklenmelerinin etyolojisi, sınıflandırılması ve tedavisi. EÜ Diş Hek Fak Derg. 2017;38:68-79.

10. Türkün LS, Türkün M. Effect of bleaching and repolishing procedures on coffee and tea stain removal from three anterior composite veneering materials. J Esthet Restor Dent. 2004;16:290-301.

11. Joiner A, Philpotts CJ, Alonso C, Ashcroft AT, Sygrove NJ. A novel optical approach to achieving tooth whitening. J Dent. 2008;36(Suppl 1):8-14.

12. Collins LZ, Naeeni M, Platten SM. Instant tooth whitening from a silica toothpaste containing blue covarine. J Dent. 2008;36(Suppl 1):21-25.

13. Joiner A. Tooth colour: A review of the literature. J Dent. 2004;32(Suppl 1):3-12.

14. Newsom SW. Hygiene and the ancient Romans. Br J Infect Control. 2004;5:25-27.

15. Brooks JK, Bashirelahi N, Reynolds MA. Charcoal and charcoal-based dentifrices:A literature review. J Am Dent Assoc. 2017;148:661-670.

16. Joiner A. Whitening toothpastes: a review of the literature. J Dent. 2010;38(Suppl 2):17-24.

17. Jassé FF, de Campos EA, Lefever D, et al. Influence of filler charge on gloss of composite materials before and after in vitro toothbrushing. J Dent. 2013;41(Suppl 5):4144.

18. Philpotts CJ, Cariddia E, Spradbery PS, Joiner A. In vitro evaluation of a silica whitening toothpaste containing blue covarine on the colour of teeth containing anterior restoration materials, J Dent. 2017;67:29-33.

19. Joiner A, Pickles MJ, Lynch S, Cox TF. The measurement of enamel wear by four toothpastes. Int Dent J. 2008;58:2328.

20. Garoushi S, Lassila L, Hatem M, et al. Influence of staining solutions and whitening procedures on discoloration of hybrid composite resins. Acta Odontol Scand. 2013;71:144150.

21. Nasim I, Neelakantan P, Sujeer R, Subbarao CV. Color stability of microfilled, microhybrid and nanocomposite resins--an in vitro study. J Dent. 2010;38:137-142.

22. Harrison JWE, Salisbury GB, Abbott DD. Effect of enzyme toothpaste upon oral hygiene. J Periodontol. 1963;34:334337.

23. Atalayın Ç, Demirhan AO, Yaşa B, Türkün LŞ. Prefabrik ve Direkt Kompozit Rezinlerdeki Renk Değişimleri Diş Fırçalaması ile Giderilebilir mi? EÜ Dişhek Fak Derg. 2018;39:46-52. 